\title{
Heteropoly acid catalyzed cyclization of nerolidol and farnesol: Synthesis of $\alpha$-bisabolol
}

\author{
Augusto L.P. de Meireles a ${ }^{a}$ Maíra dos Santos Costa ${ }^{a}$, Kelly A. da Silva Rocha ${ }^{\text {b }}$, \\ Elena V. Gusevskaya ${ }^{\mathrm{a}, *}$ \\ a Departamento de Química, Universidade Federal de Minas Gerais, 31270-901 Belo Horizonte, MG, Brazil \\ b Departamento de Química, Universidade Federal de Ouro Preto, 35400-000 Ouro Preto, MG, Brazil
}

\section{A R T I C L E I N F O}

\section{Article history:}

Received 11 March 2015

Received in revised form 26 May 2015

Accepted 17 June 2015

Available online 22 June 2015

\section{Keywords:}

Biomass-based feedstock

Homogeneous catalysis

Isomerization

Polyoxometalates

Terpenes

\begin{abstract}
A B S T R A C T
Heteropoly acid $\mathrm{H}_{3} \mathrm{PW}_{12} \mathrm{O}_{40}$ is an active and environmentally friendly homogeneous catalyst for the synthesis of $\alpha$-bisabolol, a high-priced and highly demanded ingredient for the fragrance, cosmetic and pharmaceutical industries, starting from more abundant biomass-based sesquiterpenic alcohols. The solvent nature remarkably affects the reaction pathways and product selectivity. In acetone solutions, $\alpha$-bisabolol can be obtained in 55-60\% GC yields from nerolidol and 60-70\% GC yields from farnesol at complete substrate conversions, which are probably the best results ever reported for these reactions. $\alpha$-Bisabolol synthesized by this method contains no farnesol, which is a potentially allergenic compound and should be avoided in the commercially used $\alpha$-bisabolol. This advantage is especially important because the distillative separation of $\alpha$-bisabolol and farnesol is a troublesome task. The catalyst shows high turnover numbers and operates under mild nearly ambient conditions.
\end{abstract}

(C) 2015 Elsevier B.V. All rights reserved.

\section{Introduction}

Terpenes represent an important renewable feedstock for flavor and fragrance and pharmaceutical industries [1,2]. These natural compounds are available from essential oils of many plants and fruits. Various useful terpenoid products are commercially obtained by acid-catalyzed transformations of more abundant terpenes. In many of these processes mineral acids are still used as catalysts, which results in the large amounts of waste. The development of more environmentally friendly acid catalysts for the reactions of terpenes is constantly required for the efficient valorization of bio-renewable essential oils.

$\alpha$-Bisabolol, a monocyclic sesquiterpenic alcohol with a pleasant floral-sweet aroma, is a major component of the essential oils of chamomile (Matricaria chamomilla), candeia (Eremanthus erythropappus) and sage (Salvia runcinata) oils (up to 50, 85 and $90 \%$ contents, respectively) [3-6]. $\alpha$-Bisabolol (also known as levomenol) has demonstrated a strong therapeutic potential due to its anti-inflammatory, skin-soothing, antibiotic, gastro-protective, analgesic and antioxidant properties [3-8]. The applications and pharmacological properties of $\alpha$-bisabolol have been recently

\footnotetext{
* Corresponding author. Fax: +55 3134095700.

E-mail address: elena@ufmg.br (E.V. Gusevskaya).
}

reviewed by Kamatou and Viljoen [6]. This non-toxic and nonallergenic compound is used in over 1000 cosmetic, fragrance and therapeutic products such as dermatological formulations, decorative cosmetics, shampoos, moisturizes, cleansers, antiperspirants, sunscreens and fine fragrances [9]. The natural sources of $\alpha$-bisabolol do not currently satisfy a high commercial demand and most $\alpha$-bisabolol on the market is produced synthetically from other terpenic compounds such as farnesol and nerolidol [10-13].

Nerolidol and farnesol are acyclic sesquiterpenic allylic alcohols readily available on the industrial scale. Both compounds have a delicate sweet floral odor and are widely used as fragrance and food-flavor ingredients [1]. Nerolidol and farnesol are found in essential oils of various plants and flowers, such as neroli, lemon grass and jasmine oils, and also produced industrially from acetone and acetylene [1]. The data on the synthesis of $\alpha$-bisabolol available in the literature are very scarce [11-23]. All the works (mostly patents) report the use of nerolidol or farnesol as starting materials [11-16] except for the articles describing total syntheses [17-23]. In most of the procedures, the synthesis of $\alpha$-bisabolol from farnesol or nerolidol is performed in the presence of large amounts of strong acids, usually mineral acids, and gives the product in $30-50 \%$ yields.

Heteropoly acids of the Keggin series (HPAs) are well known as attractive acid catalysts for the green synthesis of many fine and specialty chemicals [24-27]. A stronger Brønsted acidity usually 
renders HPAs higher catalytic activities than conventional acid catalysts, such as mineral acids, zeolites and ion-exchange resins. HPAs as catalysts cause less corrosion and environmental problems than mineral acids and do not promote undesirable side reactions. Even from homogeneous systems HPAs can be recovered and recycled without neutralization because they are highly soluble in polar solvents, on the one hand, and insoluble in non-polar solvents (e.g., hydrocarbons), on the other hand. For this reason, HPAs can be recovered from polar organic solutions by precipitating with a nonpolar solvent.

Previously, we have applied HPA catalysts in a variety of liquidphase reactions of terpenic compounds, such as isomerization [28-32], hydration, etherification and esterification [33-35], and cycloaddition [36]. Within our program on the valorization of natural ingredients of essential oils by catalytic transformations, we report now the application of tungstophosphoric heteropoly acid $\mathrm{H}_{3} \mathrm{PW}_{12} \mathrm{O}_{40}(\mathrm{HPW})$, the strongest HPA in the Keggin series, as a homogeneous catalyst for the isomerization of nerolidol (1) and farnesol (2) aiming to obtain $\alpha$-bisabolol (3). To our knowledge, no attempt to use HPA catalysts for these reactions has been made so far. Moreover, none of the previous works, as far as we know, have achieved such a high yield of $\alpha$-bisabolol.

\section{Experimental}

All chemicals were purchased from commercial sources and used as received, unless otherwise stated. Nerolidol $(3,7,11-$ trimethyl-1,6,10-dodecatrien-3-ol, mixture of isomers) and farnesol (3,7,11-trimethyl-2,6,10-dodecatrien-1-ol, mixture of isomers) as well as $\mathrm{H}_{3} \mathrm{PW}_{12} \mathrm{O}_{40}$ hydrate were acquired from Aldrich.

The reactions were carried out in a $10 \mathrm{~mL}$ glass reactor equipped with a magnetic stirrer and a condenser. In a typical run, the solution $(5.0 \mathrm{~mL})$ of the substrate $(0.38-1.50 \mathrm{mmol}, 0.075-0.3 \mathrm{M})$, HPW (5-20 mg, $1.65-6.67 \mu \mathrm{mol})$ and dodecane $(0.5 \mathrm{mmol}, 0.1 \mathrm{M}, \mathrm{GC}$ internal standard) in the indicated solvent was intensively stirred under air at a specified temperature $\left(15-50^{\circ} \mathrm{C}\right)$. The reaction rate was not dependent on the intensity of stirring within the range used. The reactions were followed by gas chromatography (GC) using a Shimadzu 17 instrument fitted with a Carbowax 20 M capillary column and a flame ionization detector. After an appropriate reaction time, aliquots were taken and analyzed by GC. Conversion and selectivity were determined by GC based on substrate converted. The GC mass balance was based on the charged substrate using dodecane as an internal standard. Some experiments were run for several times to confirm reproducibility. Turnover frequencies (TOF) were measured by GC at low conversions (up to $20-40 \%$ ) by taking aliquots at short reaction times. The products were identified by mass spectroscopy using a Shimadzu QP2010PLUS instrument operating at $70 \mathrm{eV}$ by comparison with authentic compounds.

\section{Results and discussion}

The results on the isomerization of nerolidol in acetone solutions containing HPW are presented in Table 1. The reaction gave $\alpha$-bisabolol with up to $66 \%$ selectivity along with small amounts of farnesol, which usually disappeared by the end of the nerolidol conversion (Scheme 1). The rest of the substrate was converted mainly in bisabolenes, which formally are the products of the dehydration of $\alpha$-bisabolol. The reactions were not significantly complicated by oligomerization, as often happens with terpenic compounds under acidic conditions.

The transformation of nerolidol in the presence of ca. $0.2 \mathrm{~mol} \%$ of $\mathrm{HPW}$ occurred smoothly at $40^{\circ} \mathrm{C}$ resulting in a nearly complete conversion for $4 \mathrm{~h}$ (Table 1 , run 1 ). However, a mixture of bisabolenes was predominantly formed under these conditions rather than the desired $\alpha$-bisabolol. The selectivity for $\alpha$-bisabolol did not exceed $40 \%$. At $50^{\circ} \mathrm{C}$, the results were even less encouraging in terms of selectivity (Table 1, run 2 ). On the other hand, to run the reaction at $30^{\circ} \mathrm{C}$ allowed to direct more efficiently the transformation of nerolidol to $\alpha$-bisabolol. The formation of farnesol in significant amounts was detected at low conversions. Then, the concentration of farnesol decreased, whereas the selectivity of $\alpha$-bisabolol increased and reached $60 \%$ at a $90 \%$ conversion (Table 1 , run 3 ).

To accelerate the reaction, the catalyst amount was increased (Table 1 , runs 4 and 5 ). In both runs, $\alpha$-bisabolol was obtained in good selectivities at $90 \%$ conversions (60-66\%). However, attempts to complete the conversion resulted in a drastic drop in $\alpha$-bisabolol selectivity ( $36 \%$ at $97 \%$ conversion; run 5 , Table 1 ). Although, farnesol was detected in the reaction solutions in significant amounts at early reaction stages (up to $30 \%$ of the converted nerolidol), final reaction mixtures contained no even traces of farnesol. Thus, a variety of reversible transformations occur with nerolidol in acetone solutions under acidic conditions. These transformations are connected in a complex manner so that a task to obtain $\alpha$-bisabolol in high selectivity becomes really challenging.

Trying to inhibit the formation of dehydration products, i.e., bisabolenes, we performed the reaction in the presence of extra water (Table 1, runs 6 and 7). However, the addition of only 1 eq. of water significantly decelerated the reaction. Moreover, the 7-fold molar excess of extra water completely suppressed the reactivity of nerolidol. A further attempt to improve the selectivity for $\alpha$ bisabolol was decreasing the reaction temperature. However, the reaction at $15^{\circ} \mathrm{C}$ was not only much slower (expectedly) but also much less selective toward the desired $\alpha$-bisabolol (Table 1 , run $8)$. The HPW recovered after the reaction by precipitation with hexane and centrifugation was reused without loss of activity and selectivity (Table 1 , run 11 ).

In summary, using the HPW catalyst, nerolidol can be converted to $\alpha$-bisabolol in 55-60\% GC yields under optimized conditions. This value is among the best results reported for this reaction so far $[11,15]$. Owing to low catalyst loading, which is an important advantage of the method along with mild reaction conditions, high turnover numbers (TONs) can be achieved in the substrate conversion (up to 450 per mol of HPW). It is very important that final reaction mixtures contain virtually no farnesol (by GC analysis). The problem is that farnesol, differently from $\alpha$-bisabolol, has an allergenic potential; therefore, its presence in cosmetic products is highly undesirable from a dermatological standpoint [37]. The purification of $\alpha$-bisabolol by distillation is difficult because $\alpha$ bisabolol and one of the isomers of farnesol (cis, cis) have almost identical boiling points. Removing farnesol from natural and synthetic $\alpha$-bisabolol for practical applications is usually performed by the selective esterification of farnesol in the mixtures and subsequent distillative separation of farnesol esters from $\alpha$-bisabolol [37-39]. It should be mentioned that $\alpha$-bisabolol synthesized in our work is most probably racemic.

Farnesol was also used as the starting material for the synthesis of $\alpha$-bisabolol in our work (Table 2). $\alpha$-Bisabolol was obtained in $60-70 \%$ GC yields, the highest values reported for the synthesis $\alpha$-bisabolol from either nerolidol or farnesol as far as we know. It is noteworthy that in the very beginning of the reaction, most of farnesol rapidly isomerized to nerolidol, which was further slowly consumed to give $\alpha$-bisabolol along with small amounts of bisabolenes. For example, in run 1 in Table 2, a 83\% conversion of farnesol occurred for $1 \mathrm{~h}$, from which $67 \%$ was converted to nerolidol, $25 \%$ to $\alpha$-bisabolol and only $8 \%$ to bisabolenes. Then, the relative amounts of $\alpha$-bisabolol gradually increased at the expense of nerolidol so that after $9 \mathrm{~h}$ a $72 \%$ selectivity for $\alpha$-bisabolol was obtained. It is important that the combined GC yield of $\alpha$-bisabolol and nerolidol was as high as $91 \%$, with only small amounts of bis- 
Table 1

Isomerization of nerolidol (1) to $\alpha$-bisabolol (3) and farnesol (2) catalyzed by HPW. ${ }^{\mathrm{a}}$

\begin{tabular}{|c|c|c|c|c|c|c|c|c|c|c|}
\hline \multirow[t]{2}{*}{ Run } & \multirow{2}{*}{$\begin{array}{l}\text { HPW } \\
(\mu \mathrm{mol})\end{array}$} & \multirow{2}{*}{$\begin{array}{l}\mathrm{T} \\
\left({ }^{\circ} \mathrm{C}\right)\end{array}$} & \multirow{2}{*}{$\begin{array}{l}1 \\
(\mathrm{mmol})\end{array}$} & \multirow{2}{*}{$\begin{array}{l}\text { Time } \\
\text { (h) }\end{array}$} & \multirow{2}{*}{$\begin{array}{l}\text { Conversion } \\
(\%)\end{array}$} & \multicolumn{2}{|c|}{ Selectivity (\%) } & \multirow{2}{*}{$\begin{array}{l}\mathrm{TOF}^{\mathrm{b}} \\
\left(\mathrm{h}^{-1}\right)\end{array}$} & \multirow[t]{2}{*}{$\mathrm{TON}^{\mathrm{b}}$} & \multirow{2}{*}{$\begin{array}{l}\text { GC yield } \\
(\%)\end{array}$} \\
\hline & & & & & & 3 & 2 & & & \\
\hline \multirow[t]{2}{*}{1} & 1.65 & 40 & 0.75 & 0.5 & 61 & 40 & - & n.d. ${ }^{a}$ & 436 & 36 \\
\hline & & & & 4 & 96 & 38 & - & & & \\
\hline 2 & 1.65 & 50 & 0.75 & 3 & 100 & 35 & - & n.d. ${ }^{a}$ & 454 & 35 \\
\hline \multirow[t]{2}{*}{3} & 1.65 & 30 & 0.75 & 3 & 37 & 55 & 22 & 68 & 414 & 55 \\
\hline & & & & 13 & 91 & 60 & 4 & & & \\
\hline \multirow[t]{2}{*}{4} & 3.30 & 30 & 0.75 & 1 & 29 & 40 & 31 & 68 & 205 & 60 \\
\hline & & & & 9 & 91 & 66 & - & & & \\
\hline \multirow[t]{2}{*}{5} & 6.60 & 30 & 0.75 & 3 & 90 & 60 & - & n.d. ${ }^{a}$ & & 35 \\
\hline & & & & 5 & 97 & 36 & - & & & \\
\hline $6^{c}$ & 3.30 & 30 & 0.75 & 7 & 0 & - & - & 0 & 0 & \\
\hline $7^{d}$ & 3.30 & 30 & 0.75 & 6 & 40 & 24 & 5 & 23 & 90 & 10 \\
\hline 8 & 3.30 & 15 & 0.75 & 5 & 50 & 17 & 3 & 45 & 114 & 9 \\
\hline 9 & 3.30 & 30 & 1.50 & 9 & 75 & 65 & 4 & 99 & 340 & 46 \\
\hline 10 & 3.30 & 30 & 0.38 & 5 & 100 & 55 & - & 70 & 115 & 55 \\
\hline $11^{\mathrm{e}}$ & 1.65 & 30 & 0.75 & 13 & 94 & 67 & - & n.d. ${ }^{a}$ & 426 & 63 \\
\hline
\end{tabular}

a Reactions were carried out in acetone solutions, with the total volume of the reaction mixture of $5.0 \mathrm{~mL}$; conversion and selectivity were determined by GC based on substrate converted; n.d. - not determined.

b TON in moles of substrate converted per mole of HPW. TOF is the initial turnover frequency (mol of the substrate converted per mol of HPW per hour).

c $100 \mu \mathrm{l}(5.55 \mathrm{mmol})$ of water was added.

d $13.5 \mu \mathrm{l}(0.75 \mathrm{mmol})$ of water was added.

e HPW recovered after run 3 by the precipitation with hexane was used as the catalyst.

abolenes being detected in the reaction solutions at this stage. Keeping the reaction mixture in the contact with the catalyst for one hour more did not result in a further increase in the $\alpha$-bisabolol yield.

Increasing the catalyst concentration allowed to accelerate the transformation of nerolidol, which was rapidly formed from farnesol at early reaction stages, to $\alpha$-bisabolol without a significant loss in selectivity for the target $\alpha$-bisabolol (Table 2, runs 2 and 3 ).
Interestingly, the combined selectivity of $\alpha$-bisabolol and nerolidol was only $49 \%$ after the complete farnesol conversion in run 3 for $1 \mathrm{~h}$, with bisabolenes accounting for the rest of the mass balance. At longer reaction times, the selectivity of $\alpha$-bisabolol increased to $70 \%$ at the expense of both nerolidol and bisabolenes showing that the formation of bisabolenes in our system is also reversible.

To improve the catalyst efficiency in terms of TONs, the amount of the starting farnesol was doubled in run 4 . In this run, $\alpha$-bisabolol
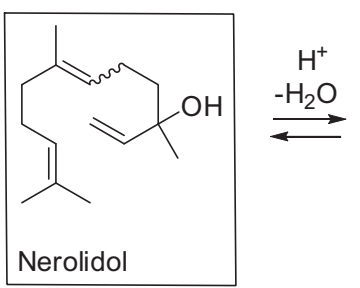

A<smiles>C#CC(C=C)CCC=C(C)CCC=C(C)C</smiles><smiles>C=C</smiles><smiles>CC(C)=CCCC(C)=CCCC(C)=CCO</smiles><smiles>CC(C)=CCCC(C)(O[C+](C)C)C1CC=C(C)CC1</smiles><smiles>C#CC=C(C)C</smiles><smiles>CC(C)=CCC=C(C)C1CC=C(C)CC1</smiles><smiles>C=[PH+]</smiles><smiles>CC(C)=CCCC(C)C1CC=C(C)CC1</smiles><smiles>CC(C)=CCCC(C)(O)C1CC=C(C)CC1</smiles>

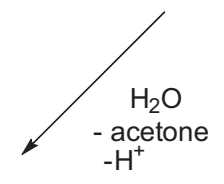

邓-Bisabolene<smiles>C=C(CCC=C(C)C)C1CC=C(C)CC1</smiles>

囚-Bisabolene

Scheme 1. Schematic representation of acid-catalyzed transformations nerolidol and farnesol. 
Table 2

Isomerization of farnesol (2) to $\alpha$-bisabolol (3) and nerolidol (1) catalyzed by HPW. ${ }^{\text {a }}$

\begin{tabular}{|c|c|c|c|c|c|c|c|c|}
\hline \multirow[t]{2}{*}{ Run } & \multirow{2}{*}{$\begin{array}{l}\text { HPW } \\
(\mu \mathrm{mol})\end{array}$} & \multirow{2}{*}{$\begin{array}{l}2 \\
(\mathrm{mmol})\end{array}$} & \multirow{2}{*}{$\begin{array}{l}\text { Time } \\
\text { (h) }\end{array}$} & \multirow{2}{*}{$\begin{array}{l}\text { Conversion } \\
(\%)\end{array}$} & \multicolumn{2}{|c|}{ Selectivity (\%) } & \multirow[t]{2}{*}{$\mathrm{TON}^{\mathrm{b}}$} & \multirow{2}{*}{$\begin{array}{l}\text { GC yield } \\
(\%)\end{array}$} \\
\hline & & & & & 3 & 1 & & \\
\hline 1 & 3.30 & 0.75 & 1910 & 83100100 & 257272 & 671911 & 227 & 72 \\
\hline 2 & 4.95 & 0.75 & 1613 & 90100100 & 306058 & 60244 & 151 & 58 \\
\hline 3 & 6.60 & 0.75 & 124 & 98100100 & 244770 & 252113 & 114 & 70 \\
\hline 4 & 3.30 & 1.50 & 112 & $90 \quad 100$ & 2260 & 476 & 454 & 60 \\
\hline
\end{tabular}

a Reactions were carried out in acetone solutions, with the total volume of the reaction mixture of $5.0 \mathrm{~mL}$; $30^{\circ} \mathrm{C}$; conversion and selectivity were determined by GC based on substrate converted.

b TON in moles of substrate converted per mole of HPW.

Table 3

Isomerization of nerolidol (1) to $\alpha$-bisabolol (3) and farnesol (2) catalyzed by HPW in different solvents. ${ }^{\mathrm{a}}$

\begin{tabular}{|c|c|c|c|c|c|c|c|}
\hline \multirow[t]{2}{*}{ Run } & \multirow[t]{2}{*}{ Solvent } & \multirow{2}{*}{$\begin{array}{l}\text { HPW } \\
(\mu \mathrm{mol})\end{array}$} & \multirow{2}{*}{$\begin{array}{l}\text { Conversion } \\
(\%)\end{array}$} & \multicolumn{2}{|c|}{ Selectivity (\%) } & \multirow{2}{*}{$\begin{array}{l}\mathrm{TOF}^{\mathrm{b}} \\
\left(\mathrm{h}^{-1}\right)\end{array}$} & \multirow[t]{2}{*}{$\mathrm{TON}^{\mathrm{b}}$} \\
\hline & & & & 3 & 2 & & \\
\hline 1 & Acetone & 3.30 & 76 & 65 & 5 & 68 & 172 \\
\hline 2 & 1,2-Dichloroethane & 3.30 & 70 & 12 & 1 & 39 & 160 \\
\hline 3 & Dichloromethane & 3.30 & 58 & 14 & 3 & 23 & 132 \\
\hline 4 & Ethyl acetate & 1.65 & 97 & 12 & - & 250 & 440 \\
\hline 5 & Acetonitrile & 4.95 & 0 & - & - & - & - \\
\hline 6 & Dimethylacetamide & 4.95 & 0 & - & - & - & - \\
\hline 7 & Dimethylformamide & 4.95 & 0 & - & - & - & - \\
\hline $8^{c}$ & Methyl ethyl ketone & 3.30 & 75 & 50 & 22 & 110 & 340 \\
\hline $9^{c}$ & Acetone & 3.30 & 70 & 52 & 15 & 99 & 320 \\
\hline
\end{tabular}

a Total volume of the reaction mixture: $5.0 \mathrm{~mL}$; nerolidol: $0.75 \mathrm{mmol}$; $30^{\circ} \mathrm{C}$; reaction time: $6 \mathrm{~h}$; conversion and selectivity were determined by GC based on substrate converted.

b TON in moles of substrate converted per mole of HPW. TOF is the initial turnover frequency (mol of the substrate converted per mol of HPW per hour).

c Nerolidol: $1.50 \mathrm{mmol}$.

was obtained in $60 \%$ GC yield at the complete substrate conversion, which corresponded to the TON of 454 per mol of HPW (Table 2, run 4). No farnesol was detected in the final solutions at the end of the reactions.

The transformations of nerolidol and farnesol presented in Tables 1 and 2 were performed in acetone solutions. The nature of the solvent was found to exert a remarkable effect on these reactions. In the runs collected in Table 3 , a variety of solvents was used in the reaction with nerolidol. None of them except methyl ethyl ketone gave results comparable in terms of selectivity with those obtained in acetone. In dichloroethane and dichloromethane solutions, nerolidol reacted smoothly at $30^{\circ} \mathrm{C}$; however, to give predominantly the mixture of bisabolenes (Table 3, runs 2 and 3). In ethyl acetate, the consumption of nerolidol was so fast that we had to decrease the amount of the catalyst (Table 3, run 4). Nevertheless, the initial turnover frequency (TOF) was ca. 4 times higher than that for the reaction in acetone (cf. runs 1 and 4, Table 3). Unfortunately, very poor selectivity for $\alpha$-bisabolol was also obtained in this solvent (ca. 10\%). In the solutions of acetonitrile, dimethylacetamide and dimethylformamide, nerolidol was stable at $30^{\circ} \mathrm{C}$ for at least $6 \mathrm{~h}$ (Table 3, runs 5-7). Then, the same runs were conducted with a stepwise increase in temperature (by $10^{\circ} \mathrm{C}$ each hour) up to $80^{\circ} \mathrm{C}$ (not shown in Table); however, the conversions did not exceed $10 \%$. $\alpha$-Bisabolol was detected in only trace amounts in all these solvents. On the other hand, the reaction in another ketonic solvent, methyl ethyl ketone, gave the results comparable with those obtained in acetone solutions in terms of both the reaction rate and selectivity for $\alpha$-bisabolol (Table 3, cf. runs 8 and 9).

A possible mechanism for the acid-catalyzed transformations of nerolidol and farnesol is shown in Scheme 1. The protonation and dehydration of nerolidol and farnesol give carbenium ions $\mathrm{A}$ and $B$, respectively, which can rearrange to each other or to bisabolyl carbenium ion $\mathrm{C}$. The latter can undergo several competing transformations: the nucleophilic attack of water to give $\alpha$-bisabolol and deprotonation to give the mixture of bisabolenes. In our reactions, mainly $\alpha$-bisabolene and $\beta$-bisabolene were detected. In principle, all carbenium ions can react with another olefin molecule present in the reaction solutions to give $C_{30}$ carbenium ions initiating an irreversible oligomerization process. Fortunately, under the conditions used in our work the reactions were not significantly complicated by oligomerization. Under optimized conditions, $\alpha$-bisabolol was obtained in 55-60\% GC yields from nerolidol and 60-70\% GC yields from farnesol in acetone solutions. Within this mechanistic scheme, the presence of water in the reaction mixtures should disfavor the formation of carbenium ions A and $B$ from nerolidol and farnesol, what was really observed in the experiments described above (Table 1, runs 6 and 7).

We have not found any correlation between the effect of solvent on the selectivity of $\alpha$-bisabolol formation in these reactions and either polarity or basicity of the solvent. The unique performance of ketonic solvents could be related to the ability of ketone to trap bisabolyl carbenium ion $\mathrm{C}$ to give carbenium ion $\mathrm{D}$ (Scheme 1). Such an interaction, suggested previously by Uneyama et al. [15] could prevent a competitive proton lost by carbenium ion $C$ to give bisabolenes, the main by-products of the process. The consequent hydrolysis of the adduct $\mathrm{D}$ would give the desired $\alpha$-bisabolol. This hypothesis for the explanation of the solvent effect in the case of acetone is pictured in Scheme 1.

\section{Conclusions}

Heteropoly acid $\mathrm{H}_{3} \mathrm{PW}_{12} \mathrm{O}_{40}$ is an efficient and environmentally benign catalyst for the liquid-phase cyclization of nerolidol and farnesol into the highly valuable $\alpha$-bisabolol. A good control of chemoselectivity can be achieved through the choice of the solvent, whose nature strongly affects the reaction pathways. In acetone solutions, $\alpha$-bisabolol was obtained in $55-60 \%$ GC yields from nerolidol and $60-70 \%$ GC yields from farnesol at complete substrate conversions. Main by-products were $\alpha$-bisabolene and $\beta$-bisabolene, also useful compounds. The results obtained are probably the best ever reported for these reactions. The catalyst shows high turnover numbers (up to 450 ), acts under mild nearly ambient conditions and, in principle, can be recycled. This simple and low cost method provides an effective route for the synthesis 
of the high-priced and highly demanded ingredient for the cosmetic and pharmaceutical industries stating from more abundant biomass-based substrates. It is very important that final solutions contain no potentially allergenic farnesol, whose concentration in the commercially used $\alpha$-bisabolol should be minimized. Further studies are targeted towards the development of solid acid catalysts resistant to leaching in polar ketone solvents in order to facilitate catalyst separation.

\section{Acknowledgments}

Financial support and scholarships from CNPq, CAPES, FAPEMIG, and INCT-Catálise (Brazil) are acknowledged.

\section{References}

[1] E. Breitmaier, Terpenes. Flavors, Fragrances, Pharmaca, Pheromones, Willey-VCH, Weinheim, 2006, pp. 1.

[2] K.A.D. Swift, Top. Catal. 27 (2004) 143-155.

[3] M.R. Gomes-Carneiro, D.M.M. Dias, A.C.A.X. De-Oliveira, F.J.R. Paumgartten, Mutat. Res. 585 (2005) 105-112.

[4] A. Pauli, Int. J. Aromather. 16 (2006) 21-25.

[5] S.P. Bhatia, D. McGinty, C.S. Letizia, A.M. Api, Food Chem. Toxicol. 46 (2008) S72-S76.

[6] G.P.P. Kamatou, A.M. Viljoen, J Am Oil Chem Soc. 87 (2010) 1-7.

[7] T. Seki, T. Kokuryo, Y. Yokoyama, H. Suzuki, K. Itatsu, A. Nakagawa, T. Mizutani, T. Miyake, M. Uno, K. Yamauchi, M. Nagino, Cancer Sci. 102 (2011) 2199-2205.

[8] A.K. Maurya, M. Singh, V. Dubey, S. Srivastava, S. Luqman, D.U. Bawankule, Curr. Pharm. Biotechnol. 15 (2014) 173-181.

[9] K. Russell, S.E. Jacob, Dermatitis 21 (2010) 57-58.

[10] O. Taglialatela-Scafati, F. Pollastro, L. Cicione, G. Chianese, M.L. Bellido, E. Munoz, H.C. Özen, Z. Toker, G. Appendino, J. Nat. Prod. 75 (2012) 453-458.

[11] D. Schatkowski, W. Pickenhagen (Symrise GmbH\&Co.), DE 10246038 (2004).

[12] K. Massonne, K.P. Pfaff, J. Schubert, G. Gottwald (BASF), DE 102005053338 (2007).

[13] K. Massonne, K.P. Pfaff, J. Schubert, G. Gottwald (BASF), DE 102005053329 (2007).

[14] C.D. Gutsche, J.R. Maycock, C.T. Chang, Tetrahedron 24 (1968) 859-876.
[15] K. Uneyama, Y. Masatsugu, T. Ueda, S. Torii, Chem. Lett. (1984) 529-530.

[16] J.D. Fourneron, J. Marc, Bull. Soc. Chim. Fr. (1981) 387-392.

[17] H. Nemoto, M. Shiraki, M. Nagamochi, K. Fukumoto, Tetrahedron Lett. 34 (1993) 4939-4942.

[18] N. Makita, Y. Hoshino, H. Yamamoto, Angew. Chem. Int. Ed. 42 (2003) 941-943.

[19] X.-J. Chen, A. Archelas, R. Furstoss, J. Org. Chem. 58 (1993) 5528-5532.

[20] T. Shono, S. Kashimura, Y. Mori, T. Hayashi, T. Soejima, Y. Yamaguchi, J. Org. Chem. 54 (1989) 6001-6004.

[21] H. Sakurai, A. Hosomi, M. Saito, K. Sasaki, H. Iguchi, J.-I. Sasaki, Y. Araki, Tetrahedron 39 (1983) 883-894.

[22] P. Weyerstahl, K. Krohn, Tetrahedron 46 (1990) 3503-3514.

[23] W. Knöll, C. Tamm, Helv. Chim. Acta 58 (1975) 1162-1171.

[24] I.V. Kozhevnikov, Catalysts for Fine Chemicals, Catalysis by Polyoxometalates, vol. 2, Wiley, Chichester, 2002.

[25] T. Ueda, H. Kotsuki, Heterocycles 76 (2008) 73-97.

[26] Y. Kamiya, T. Okuhara, M. Misono, A. Miyaji, K. Tsuji, T. Nakajo, Catal. Surv. Asia 12 (2008) 101-113.

[27] E.V. Gusevskaya, ChemCatChem 6 (2014) 1506-1515.

[28] V.V. Costa, K.A. da Silva Rocha, I.V. Kozhevnikov, E.F. Kozhevnikova, E.V. Gusevskaya, Catal. Sci. Technol. 3 (2013) 244-250.

[29] K.A. da Silva Rocha, P.A. Robles-Dutenhefner, I.V. Kozhevnikov, E.V. Gusevskaya, Appl. Catal. A 352 (2009) 188-192.

[30] K.A. da Silva Rocha, I.V. Kozhevnikov, E.V. Gusevskaya, Appl. Catal. A 294 (2005) 106-110.

[31] K.A. da Silva Rocha, J.L. Hoehne, E.V. Gusevskaya, Chem. Eur. J. 14 (2008) 6166-6172.

[32] K.A. da Silva Rocha, P.A. Robles-Dutenhefner, E.M.B. Sousa, E.F. Kozhevnikova, I.V. Kozhevnikov, E.V. Gusevskaya, Appl. Catal. A 317 (2007) 171-174.

[33] A.L.P. de Meireles, K.A. da Silva Rocha, I.V. Kozhevnikov, E.V. Gusevskaya, Appl. Catal. A 409-410 (2011) 82-86.

[34] K.A. da Silva Rocha, N.V.S. Rodrigues, I.V. Kozhevnikov, E.V. Gusevskaya, Appl. Catal. A 374 (2010) 87-94.

[35] A.L.P. de Meireles, M. dos Santos Costa, K.A. da Silva Rocha, E.F. Kozhevnikova, I.V. Kozhevnikov, E.V. Gusevskaya, ChemCatChem 6 (2014) 2706-2711.

[36] V.V. Costa, K.A. da Silva Rocha, R.A. Mesquita, E.F. Kozhevnikova, I.V. Kozhevnikov, E.V. Gusevskaya, ChemCatChem 5 (2013) 1884-1890.

[37] M. Betzer, W., Kuhn, B., Wilkening, D. Schatkowski, O. Koch (Symrise GmbH\&Co.), DE 102005051903 (2007).

[38] D. Schatkowski (Symrise GmbH\&Co.), DE 102005026768 (2006)

[39] H. Ernst, K.-P. Pfaff, K., Beck, J., Schubert, G. Gottwald, W. Krause (BASF), US $20100222606(2010)$ 